\title{
La creación de empresas individuales (trabajo autónomo) por parte de estudiantes y graduados universitarios ${ }^{1}$
}

\author{
Sonia Martín López \\ Josefina Fernández Guadaño \\ Paloma Bel Durán \\ Gustavo Lejarriaga Pérez de las Vacas \\ Carlos García-Gutiérrez Fernández \\ Escuela de Estudios Cooperativos \\ Universidad Complutense de Madrid \\ lejavaca.gus@ccee.ucm.es
}

Sumario: I. Introducción. II. El emprendimiento individual (trabajo autónomo) como vía de acceso al mercado laboral por parte de estudiantes y graduados universitarios: metodología. III. La percepción del trabajo autónomo como forma de emprendimiento por parte de estudiantes universitarios. IV. La percepción del trabajo autónomo como forma de emprendimiento por parte de profesores universitarios. V. Estudio de la percepción del trabajo autónomo como forma de emprendimiento por parte de técnicos de oficinas de emprendedores. VI. Conclusiones. VII. Bibliografía.

Resumen: En España existe un importante problema de desempleo que a raíz de la actual crisis económica se ha agravado de forma considerable durante los últimos años. Los jóvenes son uno de los colectivos más afectados por el desempleo, por lo que, ante la dificultad de encontrar empleo por cuenta ajena, el emprendimiento, y en concreto el emprendimiento individual o trabajo autónomo puede suponer una alternativa al trabajo asalariado que les permita tanto incorporarse como mantenerse en el mercado laboral. Sin embargo, los jóvenes universitarios españoles siguen mostrando una escasa vocación emprendedora. En este punto, pueden jugar un papel relevante las Universidades en las se está despertando un interés por fomentar el espí-

1 Basado en el Proyecto de Investigación: «El emprendimiento individual (trabajo autónomo) como vía de acceso al mercado laboral por parte de estudiantes y graduados universitarios», Ministerio de Empleo y Seguridad Social. Orden EES/1743/2012, Expte. N. ${ }^{\circ}$ F12069. 
ritu emprendedor, no sólo desde los propios planes de estudio, sino creándose cada vez en mayor medida estructuras de asesoramiento y apoyo, como las Oficinas de Emprededores. En este sentido, este estudio procura recabar la opinión, de los diferentes colectivos implicados: alumnos, profesores y oficinas de apoyo al emprendedor, sobre la percepción del emprendimiento individual en el ámbito universitario.

Palabras clave: Desempleo juvenil, empresarios individuales, formación, cultura de creación de empresas.

Abstract: In Spain there is a major problem of unemployment due to the current economic crisis has worsened considerably in recent years. Young people are one of the groups most affected by unemployment, so that, given the difficulty of finding paid employment, entrepreneurship, and in particular the individual entrepreneurship or self-employment can be an alternative to paid work that allows them to both incorporated as staying in the labor market. However, Spanish university students continue to show a little entrepreneurial spirit. At this point, can play an important role in universities is awakening an interest in promoting entrepreneurship, not only from their own curricula, but increasingly being created as advisory and support structures, such as the Offices of Entrepreneurship. In this sense, this study seeks to gather the views of the different groups involved: students, teachers and support offices for entrepreneurs, on the perception of individual entrepreneurship at the university level.

Key words: Youth unemployment, individual entrepreneurs, education, entrepreneurship culture. 


\section{Introducción}

En las circunstancias actuales del mercado de trabajo español, con una tasa de paro que ha pasado en los últimos cinco años del 8,5 al 26,3 por ciento según Eurostat, y donde la tasa de desempleo juvenil (menores de veinticinco años) se encuentra ya en el 56,1 por ciento desde el 18,7 de septiembre de 2007, ha cobrado especial relevancia la opción del emprendimiento como vía de acceso al mercado laboral tanto para reinsertarse en el mismo como para, en el caso de los jóvenes, acceder por primera vez a su vida laboral.

Como es conocido, en estos últimos años el deterioro de la actividad económica ha afectado al ritmo de creación de nuevas empresas con algunos leves signos de recuperación en los dos últimos años. Dicha reducción comenzó a hacerse patente en la economía española hacia mediados del año 2007 que se cerraba con una cifra de empresas creadas del 3,60 por ciento menor que la del año anterior. Es en el año 2008 cuando se evidencia en mayor medida la drástica reducción en el ritmo de creación de nuevas empresas con un cambio de tendencia en los dos últimos años según los datos del Directorio Central de Empresas (DIRCE) facilitados por el Instituto Nacional de Estadística.

Ahora bien, si tenemos en cuenta los datos de la importancia de cada forma jurídica respecto al total, se observa en la Tabla OBJ-1 anexa como más de la mitad de las empresas son personas físicas y, que, además son las únicas que han crecido en los últimos años, cuando todas las demás han disminuido, pasando de representar un 57 por ciento en 2008 a un 65 por ciento en 2012. Por tanto, el emprendimiento individual es la única forma de emprender que ha aumentado en los últimos cuatro años.

Así las cosas, ante este escenario, no exento de obstáculos y dificultades, la opción del emprendimiento individual se consolida, según los datos oficiales ofrecidos, como una alternativa para acceder al mercado laboral, contribuyendo así a dinamizar la economía, y debiendo ser capaces de transformar las circunstancias económicas desfavorables en una oportunidad, como han demostrado en recesiones previas².

Con todo, resulta crucial la formación empresarial en general y de forma particular la formación en empresas de participación. El desconocimiento generalizado por parte de los nuevos emprendedores del trabajo autónomo y de las empresas de participación hace que tengan una percepción negativa de estas formas jurídicas, y prefieran optar para

2 Puede verse: Grávalos, M.A.; Pomares, I. (2001): «La adaptación de las Sociedades Laborales a la evolución del ciclo económico. Un estudio empírico para las diferentes comunidades autónomas», CIRIEC-España, Revista Pública, Social y Cooperativa, n. 38, pp. 33-55. 
Tabla OBJ-1

Evolución del número de altas de empresas por condición jurídica

\begin{tabular}{lrrrrr}
\hline & \multicolumn{1}{c}{2012} & \multicolumn{1}{c}{2011} & 2010 & 2009 & \multicolumn{1}{c}{2008} \\
\hline Total & 334.516 & 331.264 & 321.180 & 334.072 & 410.975 \\
& 216.224 & 212.015 & 198.360 & 193.796 & 232.937 \\
Personas físicas & $65 \%$ & $64 \%$ & $62 \%$ & $58 \%$ & $57 \%$ \\
Importancia Personas Físicas sobre total & 1.215 & 1.360 & 1.478 & 1.826 & 2.343 \\
Sociedades anónimas & $0,36 \%$ & $0,41 \%$ & $0,46 \%$ & $0,55 \%$ & $0,57 \%$ \\
Importancia de las SA sobre el Total & 82.435 & 81.868 & 83.070 & 98.177 & 129.028 \\
Sociedades de responsabilidad limitada & $25 \%$ & $25 \%$ & $26 \%$ & $29 \%$ & $31 \%$ \\
Importancia de las SRL sobre el Total & 36.642 & 36.021 & 38.272 & 40.273 & 46.667 \\
Otras formas jurídicas & $11 \%$ & $11 \%$ & $12 \%$ & $12 \%$ & $11 \%$ \\
Importancia de las Otras formas sobre el Total & & & & &
\end{tabular}

Fuente: Directorio Central de Empresas (DIRCE). Instituto Nacional de Estadística. Disponible en: http://www.ine.es

la puesta en marcha de nuevas iniciativas empresariales por las formas jurídicas consideradas convencionales.

Por lo que, en este punto, las Universidades juegan un papel muy relevante procurando despertar un interés por fomentar el espíritu emprendedor, no sólo desde los propios planes de estudio, sino creándose cada vez en mayor medida estructuras de asesoramiento y apoyo, como las Oficinas de Emprededores, dirigidas a la comunidad universitaria, con el objetivo de aprovechar los conocimientos académicos, y permitir la transferencia de los resultados de investigación a la sociedad, lo que sin duda favorece la inserción de los jóvenes al mercado laboral.

En síntesis, la situación laboral actual de los jóvenes españoles, su escasa vocación emprendedora y la limitada oferta educativa en materia de emprendimiento individual existente en los planes de estudios de educación superior son factores que originan este estudio amplio que procura recabar la opinión sobre la percepción del emprendimiento individual en el ámbito universitario.

\section{El emprendimiento individual (trabajo autónomo) como vía de acceso al mercado laboral por parte de estudiantes y graduados universitarios: metodología}

Sobre la base de todo lo anterior se ha realizado un proyecto de investigación, cuya síntesis se expone, financiado por el Ministerio de Empleo y Seguridad Social cuyo objetivo ha sido tomar el pulso a los estu- 
diantes, profesores y otros miembros de instituciones de asesoramiento a emprendedores de la Universidad, y más concretamente, poner en valor el emprendimiento individual como una vía de acceso al mercado laboral. En definitiva se ha pretendido conocer:

- De una parte, si los estudiantes contemplan la posibilidad de trabajar como trabajadores autónomos cuando acaben sus estudios así como el grado de conocimiento que tienen sobre la regulación y la situación actual del trabajo autónomo.

- De otra, conocer el grado de conocimiento e involucración de profesores y otras personas relacionadas con el emprendimiento de modo que asesoren o den a conocer las especificaciones precisas para constituirse como autónomos.

Con todo, hay motivos para pensar en un cambio de percepción por parte de los jóvenes universitarios y de un cambio de cultura en el que el emprendimiento individual se configura como una salida profesional y es, en este sentido, en el que la Universidad tiene una responsabilidad muy importante tanto de formación como de fomento de la cultura emprendedora.

\subsection{Metodología utilizada}

El estudio se ha llevado a cabo en tres etapas con solapamiento temporal entre las mismas, dado que se ha dirigido la investigación a tres colectivos diferentes.

Para la primera de ellas se ha elaborado y distribuido un cuestionario a estudiantes universitarios en los estudios de la Licenciatura de Administración y Dirección de Empresas de la Universidad Complutense de Madrid. En concreto se les pasado el cuestionario a los alumnos de aquellas asignaturas en las que se estimula el espíritu emprendedor entre los estudiantes, animándoles a la creación de empresas ${ }^{3}$.

En total se han considerado para la realización del estudio 509 cuestionarios válidos representando una tasa de respuesta del 97,5 por ciento.

Entre otros, se pretende valorar la opinión de los estudiantes universitarios sobre los asuntos tales como:

3 En concreto, alumnos de las asignaturas de Dirección Financiera, Análisis y Planificación Financiera, Empresa Individual y Trabajo Autónomo, Empresas de Participación (Economía Social), Economía Financiera del Trabajo Autónomo y de las Empresas de Participación, Creación de Empresas y Organizaciones de Participación. 
- El planteamiento del futuro profesional como trabajador autónomo.

- La existencia, e importancia, de materias sobre trabajo autónomo en la Universidad.

— La valoración del conocimiento sobre el trabajo autónomo.

- Los problemas, las soluciones, las ventajas y los inconvenientes del trabajo autónomo.

En la segunda fase del estudio se ha pretendido recoger la visión de profesores y profesionales especializados en el emprendimiento individual, en el trabajo autónomo, sobre los resultados de la encuesta. En particular, se ha centrado la investigación en los integrantes de otras universidades con presencia formativa y de investigación en el asunto que nos ocupa ${ }^{4}$.

En una tercera fase se ha perseguido valorar el papel que juegan técnicos y profesionales que desde las oficinas de apoyo al emprendimiento prestan asesoramiento a los futuros emprendedores en la Universidad. En concreto, saber la percepción que tienen con relación al emprendimiento bajo empresas individuales o trabajo autónomo y su papel en el proceso de asesoramiento para que las potenciales iniciativas empresariales se concreten en este tipo de empresas. Se ha partido de la experiencia de la Oficina Complutense del Emprendedor (Compluemprende) y se ha formado un panel con las principales experiencias en este ámbito en España (CIADE, Innova, Instituto IDEAS, entre otras) ${ }^{5}$.

Con la realización de este estudio se pretende determinar también el grado de conocimiento e involucración de profesores y otras personas relacionadas con el emprendimiento de modo que asesoren, o den a conocer, las especificaciones precisas para constituirse como autónomos. La Universidad tiene responsabilidad en la formación y fomento de la cultura emprendedora, siendo la forma de trabajador autónomo probablemente la más adecuada, sobre todo teniendo en cuenta la reducida dimensión de los proyectos empresariales que se ponen en marcha, reduciéndose en la mayoría de los casos al propio promotor.

Para estas dos últimas fases la metodología elegida ha sido la realización de cuestionarios y entrevistas personales que sirven de base a una fase posterior de estudio basada en el Método Delphi.

4 La tasa de respuesta obtenida en la segunda fase ha sido del 57 por ciento, siendo el 87,35 por ciento hombres y el 17,65 por ciento mujeres de diferentes universidades españolas entre las que se encuentran: La Universidad CEU San Pablo, la Universidad Europea de Madrid, ETEA de Córdoba, Universidad de Salamanca, Universidad de Jaén, Universidad de Córdoba, Universidad de Valencia, Universidad de Alicante, Universidad de Santiago y Universidad de Granada.

5 Panel integrado por nueve expertos prescriptores de referencia. 


\section{La percepción del trabajo autónomo como forma de emprendimiento por parte de estudiantes universitarios}

\subsection{Emprendimiento y jóvenes estudiantes universitarios}

\subsubsection{EL PROBLEMA DEL DESEMPLEO ENTRE LOS JÓVENES}

Durante los últimos años, como consecuencia de la crisis económica, el problema del desempleo se ha convertido en una de las preocupaciones más importantes de la población, y en especial de los más jóvenes. Desde el año 2008 las cifras de desempleados no han parado de crecer. Así, según datos de la Encuesta de Población Activa (EPA), la cifra total de parados en el año 2012 ascendía a 5.769 .000 personas, frente a las 4.900 .000 personas del 2011, lo que supuso un incremento del 15,4 por ciento6.

Atendiendo al colectivo que nos ocupa, observamos que la tasa de paro de los menores de 25 años en España que se habría logrado reducir hasta el 18 por ciento al principio de 2007, alcanzó en el año 2011 un valor del 46,4 por ciento y la cifra continuó en ascenso hasta llegar a registrar el 54,1 por ciento a final de 2012 frente al 23 por ciento de la media de la Unión Europea (Eurostat) ${ }^{7}$.

El grupo de edad objeto del presente estudio, el comprendido entre los 20 y 24 años, es en el que más se ha incrementado la tasa de paro, en relación con años anteriores; así se ha pasado de una tasa de paro del 37,02 por ciento en el año 2010, a una del 42,60 por ciento en el año 2011 llegando al 51,68 por ciento en el año 2012.

Cabe destacar entre los factores que están empeorando la crisis de empleo de los jóvenes, y plantean desafíos para la transición hacia un trabajo de calidad se encuentran los siguientes:

- El incremento del número de «jóvenes desalentados» (no participan ni en el empleo, ni en la educación o formación), renuncian

6 http://www.ine.es/jaxiBD/menu.do?L=0\&divi=EPA\&his=3\&type=db. Fecha de consulta: 15 de octubre de 2013.

7 Datos de Eurostat Última actualización: 1 oct 2013. Véase: http://www.google.es/ publicdata/explore?ds=z807pt6rd5uqa6_\&met_y=unemployment_rate\&idim=country: es\&fdim_y=seasonality:sa\&dl=es\&hl=es\&q=tasa\%20de\%20paro\%20en\%20espa\%C3\%B1a. Fecha de consulta: 10 de octubre de 2013.

8 Oficina Internacional del Trabajo. La crisis del empleo de los jóvenes. Hechos sobresalientes del informe de la CIT 2012. Disponible en Internet en: http://www.ilo.org/wcmsp5/ groups/public/—-ed_emp/_-ed_emp_msu/documents/publication/wcms_181303.pdf; Estrategia de emprendimiento y empleo joven. Disponible en internet: http://www. empleo.gob.es/es/estrategia-empleo-joven/archivos/Analisis_de_Contexto.pdf. Fecha de consulta: 12 de octubre de 2013. 
a buscar empleo, por las bajas perspectivas de encontrarlo, y la baja calidad de los mismos. En efecto, según Eurostat, España proporciona las mayores cifras de jóvenes en esta situación. Un 18,5 por ciento de los de edades comprendidas entre 16 y 24 y un 25 por ciento de los de edades comprendidas entre los 25 y 29 años frente al 12,9 y 19,3 por ciento respectivamente de la Unión Europea.

- La condición de jóvenes desempleados de larga duración. En efecto, se ha incrementado el porcentaje de desempleados de larga duración entre los jóvenes, lo que aumenta las probabilidades de riesgo de pobreza y exclusión social. En el año 2012 casi el 35 por ciento de los jóvenes desempleados de entre 16 y 24 años se encuentran sin trabajo desde hace más de doce meses llegando al 51,64 por ciento para los jóvenes de mayor edad (25 a 29 años).

- Los jóvenes autompleados han descendido desde el año 2007 hasta la actualidad en un 53,7 por ciento frente al 11,8 por ciento de la Unión Europea.

- Los jóvenes españoles ocupan puestos de trabajo de categoría inferior a su formación académica, existiendo además un desajuste entre las competencias profesionales de los titulados y los empleos disponibles.

- Los jóvenes que están en el mercado laboral como trabajadores por cuenta ajena tienen más probabilidades de que su contrato sea de tipo temporal. Además, según se pone de manifiesto en el informe de Tendencias mundiales del empleo juvenil 2012, elaborado por la Oficina Internacional del Trabajo9 ${ }^{9}$ en la Unión Europea, que el número de jóvenes con un empleo a tiempo parcial, y con un empleo de carácter temporal, ha crecido más rápido que en el caso de los adultos, antes y durante la crisis económica.

- Por otra parte, los jóvenes que han accedido a un empleo tienen más probabilidades de ser despedidos que los adultos, y su tasa de rotación es mayor. A esto hay que sumar, que la crisis económica ha puesto en evidencia que los jóvenes son los últimos en ser contratados, y los primeros en ser despedidos, al resultar más barato su despido y tener menor experiencia profesional.

Con todo, el alto nivel de desempleo juvenil en España es un problema estructural con graves consecuencias para la situación presente

9 Puede consultarse en: http://www.ilo.org/global/research/global-reports/globalemployment-trends/youth/2012/lang—es/index.htm. Fecha de consulta: 20 de octubre de 2013. 
y futura de los jóvenes españoles y limita el crecimiento potencial de la economía española en el largo plazo lo que refuerza la necesidad de establecer medidas de apoyo al empleo y al emprendimiento.

\subsubsection{LA FORMACIÓN Y EL ACCESO AL MERCADO LABORAL EN EL CASO DE LOS JÓVENES}

La formación desempeña un papel crucial en la incorporación al mercado laboral, reduciendo la probabilidad de desempleo, y no limitando el acceso de los jóvenes sólo a puestos de trabajo de baja cualificación, y alta temporalidad, que son los más inestables ante los ajustes de las empresas en épocas de crisis. Así, el hecho de no poseer una cualificación de Educación Secundaria superior representa un serio obstáculo para encontrar trabajo, y pone de manifiesto el problema de la sobrecualificación ${ }^{10}$, por el que se ven afectados los jóvenes licenciados españoles entre 25 y 29 años, al ocupar puestos de trabajo de categoría inferior a su formación académica, y recibir salarios inferiores, siendo el porcentaje de jóvenes españoles que se encuentran en esta situación casi el doble que la media de los países de la OCDE ${ }^{11}$.

Además, España está en situación de desventaja con respecto a otros países de su entorno ${ }^{12}$ al ocupar la primera posición de Europa en términos de fracaso escolar, y tener un número insuficiente de alumnos que se matriculan en Formación Profesional de Grado medio.

\subsubsection{EL EMPRENDIMIENTO COMO SALIDA PROFESIONAL DE LOS JÓVENES}

Dadas las dificultades de encontrar trabajo por cuenta ajena, el emprendimiento se valora cada vez más positivamente como una oportunidad para incorporarse, y mantenerse en el mercado laboral, contribuyendo así a dinamizar la economía ${ }^{13}$, impulsando la innovación,

10 Informe de la Fundación Conocimiento y Desarrollo (FCyD) de 2010. Disponible en Internet en: http://www.fundacioncyd.org/index.php/informe-cyd/informe-cyd-2010

11 Informe Panorama de la Educación 2011 de la OCDE. Disponible en Internet: http://estaticos.elmundo.es/documentos/2011/09/13/ocde.pdf. Véase también: informe Education at a Glance 2011, elaborado por la OCDE. Disponible en Internet en: http:// www.oecd.org/edu/highereducationandadultlearning/educationataglance2011 oecdindicators.htm. Fecha de consulta: 15 de octubre de 2013.

12 Según datos de la UNESCO en el estudio anual publicado en 2012 sobre Educación para Todos Disponible en Internet: http://www.unesco.org/new/es/education/themes/ leading-the-international-agenda/efareport/reports/2012-skills/. Fecha de consulta: 15 de octubre de 2013.

13 Observatorio del Espíritu Emprendedor. Disponible en Internet en: http://www. emprendeinnova.org/observatorio/?menu=9. Fecha consulta: 15 de octubre de 2013. 
la competitividad y el desarrollo económico y social (ALEMANY, et al, 2011). No obstante, la decisión de emprender ha de basarse en la identificación y aprovechamiento de oportunidades, porque si sólo se valora la necesidad del empleo este tipo de emprendimiento es de peor calidad, y tiene mayor riesgo de temporalidad. El emprendimiento ha de permitir mejorar las condiciones laborales de los jóvenes, y que puedan ocupar puestos de trabajo acordes con la formación recibida. Según datos del informe GEM 2011 la consideración del emprendimiento como una buena carrera profesional se mantiene entorno a un 65,2 por ciento, y el 90,2 por ciento de los jóvenes entre 15 y 29 años, encuestados en el sondeo de opinión realizado por INJUVE, tienen una opinión positiva de las personas emprendedoras, que trabajan por cuenta propia y tienen sus propios negocios. Pero para que los jóvenes opten en mayor medida por el emprendimiento como salida profesional es necesaria una mayor cultura emprendedora, para lo que se precisa de mayor formación sobre emprendimiento.

La vocación emprendedora de los jóvenes españoles ${ }^{14}$ se sitúa por debajo de la media de sus homólogos europeos, por lo que se precisa la difusión de las bondades del emprendimiento, tales como la posibilidad de obtener empleos de calidad y estables que se adecúen en mayor medida a la formación obtenida, así como su apoyo. Los que optarían por un empleo por cuenta propia ${ }^{15}$ lo harían fundamentalmente por motivos de independencia personal, y autorrealización, y no lo harían por la situación económica actual, y el riesgo de quiebra, principalmente ${ }^{16}$.

Es necesario fomentar el espíritu empresarial desde los primeros niveles del sistema educativo ${ }^{17}$. La enseñanza reglada del emprendimiento proporciona una ganancia en el ámbito de actitudes emprendedoras de la población, que posteriormente pueden traducirse en

14 Según el informe de jóvenes emprendedores, realizado por ATA (Asociación de Trabajadores Autónomos), la tasa de emprendedores españoles menores de 30 años se sitúa en el 4 por ciento, siendo la media en Europa del 5,5 por ciento. Disponible en Internet en: http://www.ata.es/imagenes/publicacionesPdf/publicacion55.pdf.

15 Sondeo de opinión sobre Jóvenes y emprendimiento 2012, realizado por INJUVE.

16 Según datos del informe Flash Eurobarometer 283 publicado en el año 2010, en el año 2009 el 40 por ciento de los españoles preferían el autoempleo. Disponible en Internet en: http://ec.europa.eu/public_opinion/flash/fl_283_en.pdf. Fecha consulta: 15 de octubre de 2013.

17 Hay que aprovechar el interés y la ilusión de los jóvenes por la iniciativa emprendedora en edades tempranas. Véase en la encuesta realizada por ESADE a 7.000 jóvenes en marzo de 2011 que se recogen en el Libro Blanco de la iniciativa emprendedora en España cuando resulta interesante para los jóvenes la opción de dirigir un negocio propio. 
una mayor involucración de la población en el proceso emprendedor, y también en beneficio en el sentido de promover el emprendimiento de calidad $^{18}$.

Los países de la Unión Europea se han mostrado sensibles a la promoción de la educación para el emprendimiento ${ }^{19}$, pero, a pesar de que se está tomando conciencia de la importancia de la promoción de la educación para el emprendimiento, todavía la educación y la formación emprendedoras, tanto en la etapa escolar como en la posterior, son inadecuadas en la mayoría de los países ${ }^{20}$.

En el presente informe se analizará la percepción que tienen los jóvenes estudiantes universitarios del emprendimiento, centrándonos para ello en una muestra de estudiantes de la Universidad Complutense de Madrid.

\subsection{Resultados del estudio}

Las principales conclusiones de esta fase del estudio son las siguientes:

- El 63,06 por ciento de los entrevistados se ha planteado como futuro profesional ser trabajador autónomo siendo la elección sensiblemente superior en el caso de los hombres.

- Los motivos que manifiestan como más destacados son el carácter independiente de los trabajadores autónomos (30,65 por ciento de los casos) que se refuerza con la valoración positiva de ser su propio jefe (27,11 por ciento), la libertad (25,34 por ciento) y la autorrealización como emprendedores (23,77 por ciento). En segundo lugar, motivos relacionados con la posibilidad de obtener mayores ingresos (un 20,83 por ciento.

- La situación actual de crisis económica sólo animaría a los encuestados a emprender como trabajadores autónomos al 15,72 por ciento de los encuestados.

18 Informe GEM 2011 (Global Entrepreneurship Monitor) sobre emprendimiento. Disponible en Internet en: http://www.gemconsortium.org/docs/download/2262. Fecha consulta: 15 de octubre de 2013.

19 Informe publicado por la Comisión Europea en abril de 2012. Disponible en Internet en: http://europa.eu/rapid/press-release_IP-12-365_es.htm. Fecha de consulta: 15 de octubre de 2013.

20 Esta percepción es ratificada por el sondeo de opinión sobre Jóvenes y emprendimiento 2012, realizado por INJUVE, el Instituto de la Juventud, en el año 2012 a jóvenes entre 15 y 29 años. Disponible en Internet en: http://www.injuve.es/observatorio/ formacion-empleo-y-vivienda/jovenes-y-emprendimiento-2012. Fecha de consulta: 15 de octubre de 2013. 
- Los estudiantes universitarios no tienen en cuenta prácticamente las facilidades que puedan establecerse para el emprendimiento universidad en tanto a fiscalidad, facilidad en la tramitación o menores costes en la puesta en marcha de la actividad empresarial.

- Por sexo, los hombres valoran en mayor medida la posibilidad de obtener ingresos por el desarrollo de la actividad mientras que las mujeres valoran el emprendimiento individual como consecuencia de los bloqueos en el ascenso laboral, el denominado techo de cristal.

- Los motivos por los cuales los estudiantes universitarios no consideran su futuro profesional como trabajadores autónomos son de forma mayoritaria las preferencias por trabajar bien en empresas privadas como trabajadores por cuenta ajena (bancos, consultorías, etcétera) o como funcionarios públicos opositando a los distintos cuerpos de la Administración; la aversión al riesgo y la búsqueda de seguridad laboral condicionan en gran medida su planteamiento.

- Un 12 por ciento de los entrevistados no se ha planteado aún su futuro profesional.

- La mitad de los entrevistados mantendría relaciones profesionales con trabajadores autónomos siendo las relaciones con proveedores autónomos la condición que se establece mayoritariamente. Un 26,02 por ciento indica que se relacionaría con sus compañeros de trabajo.

- La mitad de los estudiantes entrevistados desconoce si en su centro de estudio se imparten materias relacionadas con el trabajo autónomo; no obstante el 92,93 por ciento considera que estas materias debieran impartirse en su centro de enseñanza lo que supone un interés especial en el emprendimiento individual. La carrera que los estudiantes consideran mayoritariamente que ha de contener estas materias específicas en la Licenciatura y Grado de Administración de Empresas.

- Aproximadamente 1 de 4 estudiantes universitarios encuestados con formación empresarial no reconocen la condición empresarial del trabajo autónomo. Por lo que resulta necesario reforzar en el sistema educativo la educación en materia de emprendimiento.

- El desconocimiento de la figura del trabajador autónomo se acentúa en la medida en la que se profundiza en cuestiones más específicas como la Ley del Estatuto del trabajo autónomo, la prestación por cese de actividad, o las características de las figuras del trabajador autónomo económicamente dependiente, y el falso autónomo. 
- A pesar del peso que tiene el sector servicios en el tejido empresarial español, sólo han seleccionado este sector como en el que desarrollan su actividad económica la mayor parte de los trabajadores autónomos menos del 70 por ciento de los encuestados, asociando en el 22,46 por ciento de los casos la figura del trabajador autónomo al sector primario.

- Los estudiantes encuestados han identificado mayoritariamente las actividades económicas dentro de cada sector de actividad en las que hay mayor presencia de trabajadores autónomos. Destacando la agricultura, la ganadería, la pesca y la caza, en el sector primario, la construcción, y la industria electrónica e informática, en el sector secundario, y el comercio, la hostelería, y el transporte, en el sector servicios.

- La fiscalidad del trabajo autónomo es una gran desconocida. El 58 por ciento de los estudiantes la desconoce.

- Los principales problemas del trabajo autónomo son el acceso a la financiación, considerado como el de mayor de envergadura por el 49,89 por ciento de los entrevistados y la competitividad en un 29,68 por ciento de los casos.

- Otros problemas que los estudiantes refieren son: el riesgo, los problemas derivados de la enfermedad y bajas laborales, el futuro de sus pensiones, la inseguridad en el cobro a los clientes, la burocracia en los trámites y la a falta de prestaciones sociales, en general.

- Las soluciones valoradas como más efectivas son las relacionadas con la financiación: el incremento de las subvenciones y las facilidades de las condiciones de los préstamos incluyendo líneas ICO.

- Las soluciones que puedan venir de la mano de la creación de redes son valoradas como más efectivas por el 80 por ciento de los estudiantes.

- El 81,62 por ciento considera a la economía sumergida como una amenaza para el trabajador autónomo siendo los sectores de la agricultura, la construcción, la hostelería y los transportes los sectores más afectados coincidiendo su percepción con los estudios realizados.

- La pertenencia a asociaciones representativas de trabajadores autónomos como solución a los problemas derivados del aislamiento y el individualismo del trabajo autónomo es valorado positivamente por el 68 por ciento de los entrevistados.

- Las ventajas que se consideran más importantes de los trabajadores autónomos son la independencia, libertad de decisión y control del negocio, seguida de la flexibilidad en la organización 
y prestación del trabajo. Mientras que quedarían en un segundo plano las obligaciones contables y fiscales más sencillas, y el hecho de que se requieran menores trámites y gastos de constitución, ventajas que, sin embargo, son más valoradas por aquellos que realmente se están planteando la opción de emprender, y analizan las formas jurídicas disponibles para materializar su proyecto empresarial.

- Otras ventajas a las que hacen referencia los encuestados son la posibilidad de conseguir un mayor salario, el autocontrol y la autorresponsabilidad, la dirección propia, los mayores beneficios que dependen del trabajo de uno mismo, y la autorrealización en el trabajo.

- Los estudiantes universitarios han de considerar el trabajo autónomo como una salida profesional que les permita obtener un empleo de calidad, y adecuar el puesto de trabajo ocupado al nivel de formación recibido.

- Los inconvenientes a los que los estudiantes universitarios encuestados dan mayor importancia son la variabilidad del volumen de ingresos, la asunción del riesgo del negocio, la responsabilidad limitada, y en menor medida las dificultades de acceso a la financiación ajena debido a las garantías exigidas. Mientras que los inconvenientes que se les otorga menor importancia son la reducida dimensión, y el hecho de tener que trabajar más horas que siendo trabajador asalariado.

- La aversión al riesgo manifestada por los estudiantes dificulta el establecimiento por cuenta propia.

- Otros inconvenientes señalados por los encuestados son la desprotección laboral, y el tener una menor protección frente al desempleo y por menor tiempo.

- Valoran positivamente la medida del pago único de la prestación por desempleo para la puesta en marcha de iniciativas empresariales como trabajadores autónomos, y consideran mayoritariamente que se debería ampliar el límite general que se puede destinar a financiar la inversión inicial. Dicho límite se ha eliminado para los hombres con edad de hasta 30 años, y las mujeres hasta 35 años, pero el colectivo que más se beneficia de esta medida es el comprendido entre los 35 y los 45 años de edad, por lo que los desempleados de este tramo de edad estás en situación de desventaja frente a aquellos desempleados que pasen a ser socios de una sociedad cooperativa de trabajo asociado, o de una sociedad laboral, a los que no se les aplica limitación alguna. 


\section{La percepción del trabajo autónomo como forma de emprendimiento por parte de profesores universitarios}

\subsection{Introducción}

Se pretende analizar el grado de conocimiento e involucración del profesorado de la Universidad con el emprendimiento, de modo que asesoren o den a conocer a los alumnos las especificaciones precisas para constituirse como trabajadores autónomos, porque la Universidad tiene una responsabilidad en la formación y fomento de la cultura emprendedora ineludible máxime teniendo en cuenta la elevada tasa de desempleo juvenil.

Ha habido tradicionalmente un déficit en los Planes de Estudios Universitarios en materias relacionadas con el emprendimiento, la cultura emprendedora, etcétera. Luego no es extraño que los profesores de Universidad no perciban mayoritariamente que los egresados universitarios se planteen como primera salida profesional el autoempleo.

Ahora bien, las circunstancias económicas actuales están suponiendo un cambio de paradigma, con una reorientación de los servicios del Estado de Bienestar, con una reducción considerable del empleo en las Administraciones Públicas, y las dificultades de los jóvenes de encontrar trabajo en las empresas españolas, son factores que contribuyen a que los estudiantes contemplen el autoempleo como una fórmula para poder trabajar con más posibilidades que antaño.

El profesorado tiene una oportunidad única para implicarse más que nunca con el alumnado y motivarles, formarles y apoyarles en el desarrollo de iniciativas empresariales. Formar líderes capaces de identificar, investigar y analizar los procesos de inversión y preparar profesionales más proactivos en la innovación y puesta en marcha de iniciativas empresariales viables. El profesorado percibe que debe implicarse en la identificación de conocimientos, habilidades, destrezas y aptitudes que faciliten y fomenten el emprendimiento.

\subsection{Resultados del estudio}

El estudio realizado pretende conocer la percepción que tiene el profesorado universitario que imparte materias relacionadas con el emprendimiento individual o colectivo acerca del espíritu emprendedor de los estudiantes. 


\section{a) Percepción sobre su futuro profesional}

Empieza a detectarse una reorientación de los jóvenes universitarios hacia el emprendimiento individual que se configura como una salida profesional. Este cambio es percibido por el profesorado, y es, en este sentido, en el que la Universidad tiene una responsabilidad muy importante tanto de formación como de fomento de la cultura emprendedora.

Aunque más del 50 por ciento del profesorado cree que el alumnado si concibe el trabajo autónomo como una salida profesional en su futuro, sin embargo, su percepción es que no es una opción que se lo plantee un porcentaje mayoritario de alumnos.

Entre los motivos que el profesorado considera que más valoran los alumnos para decantarse por esta opción en su futuro profesional se encuentra la libertad e independencia que otorga el trabajo por cuenta propia frente al trabajo por cuenta ajena y la situación actual del mercado de trabajo incapaz de absorber todos los egresados universitarios.

Por otra parte, el profesorado que considera que los alumnos no se plantean su futuro profesional como trabajadores autónomos cree que es por alguno de los motivos que se relacionan a continuación:

— La falta de vocación emprendedora.

— La falta de motivación.

- Las mayores expectativas salariales en el trabajo por cuenta ajena

- La importancia de la seguridad sobre todo al principio de su carrera profesional y sólo se plantean emprender en caso de no encontrar trabajo.

- La creencia de que la crisis es algo coyuntural y que cuando pase se restablecerá la oferta de empleo público y privado.

Todavía el profesorado considera que los discentes prefieren trabajar para una gran empresa nacional o multinacional antes que trabajar por cuenta propia. Sin embargo, tienen una percepción distinta, que supone una reorientación de preferencias, puesto que en tercer lugar, aparece la opción de crear su propia empresa antes que trabajar para el Estado. Seguramente las circunstancias actuales influyen mucho en el cambio de percepción, ya que, por la crisis el trabajo en la Administraciones Públicas ha sufrido un fuerte deterioro.

b) Percepción sobre el nivel de conocimiento que los estudiantes universitarios tienen del trabajo autónomo

Se ha constatado que hay una limitada oferta educativa en materia de emprendimiento individual existente en los Planes de Estudios de Educación Superior a pesar de ser la fórmula mayoritaria elegida de 
facto para emprender según los datos aportados por las estadísticas del INE. No obstante, se ha realizado un importante esfuerzo en los últimos años por potenciar el emprendimiento desde la Universidad y esto se ve reflejado en la opinión de los expertos.

El profesorado considera que los alumnos tienen un grado de conocimiento bajo de la figura del trabajador autónomo, tanto por falta de adaptación de los contenidos de las asignaturas a las especificidades del trabajo autónomo, como por falta de materias específicas en los Planes de Estudio que se deberían incluir en todas las carreras pero sobre todo en ADE, Derecho, ECO y Relaciones Laborales.

\section{c) Percepción sobre los problemas de los trabajadores autónomos}

Los trabajadores autónomos se enfrentan a problemas similares a los del resto de formas jurídicas de empresa, pero, también hay algunos propios derivados fundamentalmente de su dimensión.

Los expertos han destacado, en cuanto a los problemas más significativos, el de la financiación es el más importante para el 76,47 por ciento, seguido de los problemas de intercooperación (47,06 por ciento), y el retraso en el pago de las AAPP (47,06 por ciento), junto con los problemas de desconocimiento de la propia fórmula empresarial $(41,18$ por ciento). Los problemas de falta de asociacionismo, ámbito de actuación de carácter local y competitividad les siguen en importancia.

d) Percepción de las posibles soluciones a los problemas de acceso a la financiación por parte de los trabajadores autónomos

El problema de la financiación siempre se ha considerado por parte del colectivo de trabajadores autónomos el más importante de los escollos que tienen que salvar para conseguir sobrevivir pero, en los últimos años, la crisis lo ha convertido en el detonante del cierre de los pequeños negocios. Las limitaciones de la financiación se han extendido al corto plazo provocando una auténtica asfixia financiera.

Una mayor financiación mediante instrumentos adaptados a las particularidades de un colectivo que está excluido por su propia dimensión y limitaciones de capital propio de los mercados organizados de capitales es un reto en sí mismo. Tradicionalmente la falta de garantías patrimoniales para acceder a una financiación adecuada y el excesivo endeudamiento a corto plazo han dificultado el desarrollo de la actividad de la gran mayoría de los trabajadores autónomos

Siendo el problema de la financiación el más relevante, les preguntamos por las soluciones que consideran más efectivas para mejorar el 
acceso de los trabajadores autónomos a los recursos financieros que necesitan para llevar a cabo su actividad, y las respuestas, ponen de relieve que facilitar las condiciones de los préstamos otorgados por las entidades financieras así como las creación de productos específicos (76,47 por ciento) es la propuesta más relevante, seguida de la creación de redes de cooperación con otros trabajadores autónomos que faciliten los préstamos entre los participantes y de facilitar el acceso a las líneas de financiación del ICO que han tenido el mismo porcentaje de respuesta ( 58,82 por ciento).

El 41,18 por ciento considera que se tiene que incrementar el porcentaje de la cantidad percibida en pago único de la prestación por desempleo para financiar el inicio de actividad y extenderse a todo los que quieran optar por esta posibilidad con independencia de la edad y el sexo.

Por último, las subvenciones han sido una opción muy minoritaria $(11,76$ por ciento). El negocio tiene que ser viable sin tener en cuenta los recursos financieros públicos que se puedan conseguir porque no se tiene seguridad en su concesión y no se pueden condicionar inversiones empresariales a su consecución.

\section{e) Percepción de cómo la crisis ha incluido en la economía sumergida}

Los expertos también consideran que la economía sumergida, que se ha incrementado con la crisis económica, representa una seria amenaza para el negocio de los trabajadores autónomos. Más en unas actividades económicas que en otras, destacando la construcción, el comercio, el transporte, la hostelería y las actividades recreativas y artísticas.

f) Percepción de la utilidad de pertenecer a una asociación representativa de trabajadores autónomos

En el asociacionismo también observan una solución para la defensa de los intereses de los trabajadores autónomos ante las AAPP y otras instituciones. El colectivo de trabajadores autónomos ha sido siempre el más numeroso en España pero el más desprotegido, precisamente, porque ha sido uno de los más desorganizados. En los últimos años se han conseguido muchas de sus reivindicaciones históricas como disponer de una legislación propia, la LEY 20/2007, de 11 de julio, del Estatuto del trabajo autónomo (LETA). Ley novedosa en el marco del derecho comparado europeo que supone la unidad normativa en la materia y que ha otorgado el protagonismo social que merece esta 
forma de hacer economía. La Ley apuesta por el fomento y la promoción del trabajo autónomo, como una nueva obligación jurídica de las Administraciones Públicas siendo las organizaciones representativas las encargadas de defender los intereses del colectivo.

\section{g) Percepción de las ventajas e inconvenientes de ser trabajador autónomo}

Entre las ventajas más importantes que señala el profesorado destacan: la independencia, libertad de decisión y control del negocio con un 88,24 por ciento, seguido de la flexibilidad en la organización y prestación del trabajo con un 76,47 por ciento. Los menores trámites administrativos y gastos de constitución y las obligaciones contables y fiscales más sencillas lo destacan un 5,88 por ciento.

Por otro lado, respecto a los inconvenientes, la variabilidad de los ingresos (82,35 por ciento) y asumir íntegramente el riesgo del negocio $(64,71$ por ciento) son los más destacados por el profesorado, seguido con igual porcentaje de la financiación (58,82 por ciento) y la responsabilidad ilimitada del trabajador autónomo por las deudas sociales (58,82 por ciento).

h) Percepción de la medida de política activa de empleo consistente en el pago único de la prestación por desempleo en lo que afecta a la posibilidad de constituirse como trabajador autónomo

La medida del pago único de la prestación por desempleo, permite a los desempleados, ante la dificultad de acceso al crédito bancario, poder obtener los recursos financieros que necesitan para poner en marcha una iniciativa empresarial por cuenta propia, por lo que resulta una medida de gran valor especialmente en las circunstancias adversas actuales.

El 100 por ciento del profesorado coincide y considera positiva la medida del pago único de la prestación por desempleo para la puesta en marcha de iniciativas empresariales como trabajador autónomo. Si bien, el 64,71 por ciento cree que se debería ampliar, el 23,53 por ciento que es insuficiente el porcentaje actual, y el 11,76 por ciento considera que es suficiente.

\section{i) Percepción del apoyo al emprendimiento desde la Universidad}

Por último, el interés institucional de la Universidad por el emprendimiento se pone de manifiesto a través de la creación de estructuras de apoyo y asesoramiento orientadas a la comunidad universitaria. Se 
trata de las oficinas de apoyo a los emprendedores que contribuyen al desarrollo de nuevas iniciativas empresariales.

Por tanto, se considerada muy importante que el profesorado sepa de su existencia y conozca sus objetivos y funcionamiento para poder derivar a los alumnos que tengan un proyecto. En este sentido, el resultado de la encuesta es muy positivo puesto que el 94 por ciento manifiesta que conoce alguna estructura de apoyo al emprendimiento en su Universidad mientras que el resto no.

\section{Estudio de la percepción del trabajo autónomo como forma de emprendimiento por parte de técnicos de oficinas de emprendedores}

\subsection{Emprendimiento y Universidad ${ }^{21}$}

\subsubsection{EL CRECIENTE INTERÉS DE LA COMUNIDAD UNIVERSITARIA POR EL EMPRENDIMIENTO}

Hasta hace no muchos años ha sido patente el escaso interés hacia la figura del emprendedor en el ámbito universitario. Sin embargo, el estudio y la investigación en el ámbito de la capacidad emprendedora se está consolidando en los últimos años siendo abordado desde distintas áreas de conocimiento. Esto se concreta de muy diversos modos:

- En primer lugar, la aparición en primera instancia de artículos diseminados sobre el asunto que se ha ido generalizando paulatinamente hasta la aparición de números monográficos en revistas especializadas en Dirección y Administración de Empresas 22 .

- Llamada a ponencias sobre emprendedores para defensa en mesas de trabajo creadas al efecto en Congresos de Asociaciones Científicas ${ }^{23}$.

21 Ver: Martín López, S.; Fernández Guadaño, J.; Bel Durán, P.; Lejarriaga Pérez de las Vacas, G. «Necesidad de medidas para impulsar la creación de las empresas de participación desde los diferentes niveles de enseñanza», Revista CIRIEC-España. En prensa.

22 Es el caso, por ejemplo, de la Revista Europea de Dirección y Economía de la Empresa que dedica su número 2 del año 2010 (Vol. 19) al Proyecto GEM: Medición de la capacidad emprendedora.

23 La Academia Europea de Dirección y Economía de la Empresa, por ejemplo, dedica un área de trabajo con mesas específicas de sus Congresos a la creación de empresas e iniciativas empresariales. Véase: http://www.aedem-virtual.com/. Fecha de consulta: 8 de octubre de 2013. 
- Organización de cursos de verano sobre emprender desde la Universidad dirigidos tanto a alumnos como a investigadores que tienen en proyecto la creación de empresas de base tecnológica ${ }^{24}$.

- Desarrollo proyectos de investigación internacionales financiados con la participación de grupos de investigación españoles.

Hoy por hoy, por tanto, se constata un interés creciente por parte de los investigadores y docentes sobre el emprendimiento ${ }^{25}$ y a ello se suma el interés institucional de la propia Universidad. Las universidades españolas se muestran proclives cada vez en mayor medida a fomentar el espíritu emprendedor, el emprendimiento, dentro del entorno universitario, participando en redes dirigidas a fomentar el emprendimiento universitario ${ }^{26}$, poniendo en común experiencias de éxito ${ }^{27}$, y creando estructuras de asesoramiento y apoyo orientadas a la comunidad universitaria.

\subsubsection{El Simposio sobre Educación EMPREndedora como ReFEREnCia DE ENCUENTRO UNIVERSITARIO EN MATERIA DE DIFUSIÓN DE CULTURA EMPRENDEDORA}

Como ejemplo de foro de encuentro entre Universidades interesadas en fomentar el emprendimiento dentro de sus ámbitos de competencia cabe destacar el Simposio sobre Educación Emprendedora (see u!) organizado por la Fundación Universidad-Empresa (FUE) los días 18 y 19 de septiembre de 2012 en el colegio oficial de arquitectos de Madrid.

24 Entre otros, el encuentro de verano "Universidad y Emprendizaje», que tuvo lugar los días 16, 17 y 18 de julio, celebrado en el marco de los Cursos de Verano del Escorial 2008 y organizado por Compluemprende, con el patrocinio de la Agencia de Desarrollo «Madrid Emprende» del Ayuntamiento de Madrid, y la colaboración de la Escuela de Estudios Cooperativos, y la Cátedra de Empresa Individual y Trabajo Autónomo de la Universidad Complutense de Madrid.

25 Término aceptado por la Real Academia Española de la Lengua en su avance de la vigésimo tercera edición del diccionario Véase: http://lema.rae.es/drae/?val=emprendimiento. Fecha de consulta: 16 de octubre de 2013.

26 Es el caso de RedEmprendia, red iberoamericana de Universidades a la que se hará referencia más adelante. Recientemente Redemprendia ha organizado en Madrid un foro de inversión con gran éxito de participación y de movilización de capital inversor denominado Spin2012. Véase http://www.redemprendia.org/ y https://redemprendia. webcasting-studio.net/event/?t=ZjQ2MjMxN2RhMmY4MzgxNGlyZmQ4MGYzMTQ3M DMzZWMxYWQ3NWQyYw==\&e=177\&a=5\&pt=233. Fecha de consulta: 1 de septiembre de 2013.

27 Como el Simposio de Educación Emprendedora organizado por la Fundación Universidad Empresa al que se hace referencia a continuación. Véase: http://www.fue. es/seeu/presentacion.asp. Fecha de consulta: 13 de octubre de 2013. 
En foro contó con la colaboración de la Cámara Oficial de Comercio e Industria de Madrid y de la Confederación Empresarial de Madrid CEOE (CEIM), así como de las diecisiete universidades españolas con presencia en la Comunidad de Madrid.

Como objetivo fundamental del Simposio se trataba de ofrecer una imagen global de los esfuerzos que se están realizando en la universidad española en el ámbito de la educación emprendedora propiciando una puesta en común de experiencias que pudiera contribuir a un mayor y más eficaz desarrollo del emprendimiento universitario.

Son numerosas y de indudable interés las conclusiones alcanzadas en el encuentro 28 , y fueron trasladadas oportunamente a las autoridades educativas de las diferentes Administraciones Públicas, para la puesta en marcha de nuevas políticas educativas en la materia.

Entre ellas destacar:

- La iniciativa de las administraciones es fundamental para alcanzar un impacto global y no a través de hechos aislados. Ya se ha hecho referencia y se está apreciando un cambio notable.

- España debe sumarse a los ocho países europeos que ya han incorporado el emprendimiento en sus planes de estudio, aprovechando la iniciativa europea Emprendimiento 2020, teniendo en cuenta que, según los datos que maneja la Dirección General de Empresa e Industria de la Comisión Europea, la consecuencia es una mayor posibilidad de acceder al mercado laboral y de crear empresas (tasa del 20 por ciento en creación de empresas. Aspecto muy deseable pero ciertamente complejo por las dificultades financieras por las que atraviesa nuestra Universidad.

- La Universidad necesita que se introduzcan contenidos emprendedores en las fases educativas previas para maximizar su impacto animando la creatividad desde la misma infancia, edad en la que se forja el carácter. Se trata este de un asunto de capital importancia. Desde la Universidad se puede contribuir a estimular a estudiantes a emprender prestando formación y asesoramiento necesarios, pero la base del emprendimiento está en la cultura emprendedora y el óptimo es que esta se transmita a las personas en edad temprana, tanto en los primeros niveles de enseñanza como en el entorno familiar.

- El complemento imprescindible para la formación en herramientas y metodologías son las competencias que puedan educar en

28 Disponibles en: http://www.fue.es/seeu/index1.asp. Fecha de consulta: 13 de octubre de 2013. 
actitudes. Indiscutiblemente este es un asunto a resolver que pasa por transmitir adecuadamente a los docentes e investigadores la importancia del emprendimiento. Bastaría con dar a conocer la importancia del emprendimiento individual en España que se concreta en que el casi el 65 por ciento de las nuevas empresas son personas físicas (empresas individuales o trabajadores autónomos propiamente dichos).

- La formación de formadores cuenta con un papel preponderante debiendo tener cabida la formación en emprendimiento en los planes de estudio de las facultades de profesorado así como en los Magister para profesores de secundaria. También es fundamental la formación de los prescriptores en el ámbito universitario, que permita que conozcan la realidad de los potenciales emprendedores (fundamentalmente estudiantes universitarios) y las diferentes opciones de emprendimiento posibles (entre las que el trabajo autónomo o empresa individual no es suficientemente conocida - persisten muchos tópicos y se desconocen aspectos muy importantes contemplados en la actualmente vigente Ley del Estatuto del Trabajo Autónomo-29).

- Los Trabajos de Fin de Grado y de Fin de Máster deberían estar abiertos a proyectos emprendedores de estudiantes recibiendo el apoyo institucional que necesitan. Esto está empezando a ser así en muchas universidades en las que ya los nuevos estudios de grado se encuentran en su último curso.

La progresiva generalización de eventos como el Simposio de Educación Emprendedora está contribuyendo a avanzar significativamente en concienciar institucionalmente a las universidades sobre la necesidad de dotarse de estructuras de apoyo al emprendimiento como las que forman parte de este estudio (Compluemprende, CIADE, IDEAS, Uniemprende, fundamentalmente).

\subsubsection{LA RedEMPRENDIA}

En el campo de emprendimiento universitario un hecho singularmente relevante ha sido la creación de RedEmprendia, red integrada por 20 Universidades iberoamericanas que cuenta con el apoyo de Universia y el Banco de Santander que tiene como objetivo estratégico

29 Ley 20/2007, de 11 de julio, del Estatuto del Trabajo Autónomo. Véase: http:// www.boe.es/diario_boe/txt.php?id=BOE-A-2007-13409. Fecha de consulta: 14 de octubre de 2013. 
fundamental «Trasladar la apuesta por una «Universidad Emprendedora» a todos los países de Iberoamérica y a sus universidades, ayudando a crear una fuerte cultura de la innovación y el emprendimiento en las comunidades universitarias, que se traslade también a la sociedad y que sea institucionalizada como una nueva e imprescindible misión, al igual que lo es la docencia y la investigación» ${ }^{30}$. En esta red se encuentran representadas la mayor parte de las Universidades españolas que cuentan con oficinas técnicas de apoyo a emprendedores (e incluso algunas que no las tienen aún pero que cuentan con OTRIs muy activas vinculadas a parques científicos).

Más allá de los proyectos concretos, la principal aportación de Redemprendia son las sinergias derivadas de la participación de las diferentes universidades en una red de esta envergadura en la que están implicadas 20 universidades, siendo sus Rectores los integrantes de la Junta Directiva que se reúne anualmente ${ }^{31}$ y llevándose a cabo dos reuniones anuales del Comité Técnico encargado del desarrollo de los diferentes proyectos ${ }^{32}$.

El mandato recogido en la Ley 14/2013, de 27 de septiembre, de apoyo a los emprendedores y su internacionalización.

La recientemente aprobada Ley 14/2013, de 27 de septiembre, de apoyo a los emprendedores y su internacionalización 33 , se hace eco de lo referido en los apartados anteriores en sus artículos 5 y 6 .

El artículo 5 versa sobre el emprendimiento en las enseñanzas universitarias, y en él se recoge expresamente que "se promoverán las iniciativas de emprendimiento universitario para acercar a los jóvenes universitarios al mundo empresarial» y que las universidades deberán fomentar «la iniciación de proyectos empresariales, facilitando información y ayuda a los estudiantes, así como promoviendo encuentros con emprendedores». Para esto último es preciso contar con personal especializado y crear estructuras de apoyo específicas como las que se comentarán más adelante.

Por su parte, en el artículo 6 se trata de la necesaria formación del profesorado en materia de emprendimiento. En su apartado 1 se dice

30 Véase: http://www.redemprendia.org/quienes-somos/mision-y-vision. Fecha de consulta: 1 de septiembre de 2013.

31 Véase: http://www.redemprendia.org/quienes-somos/junta-directiva. Fecha de consulta: 1 de septiembre de 2013.

32 Véase: http://www.redemprendia.org/quienes-somos/comite-tecnico. Fecha de consulta: 1 de septiembre de 2013.

33 España. Ley 14/2013, de 27 de septiembre, de apoyo a los emprendedores y su internacionalización. B.O.E., 233, de 28 de septiembre. 
que «el personal docente que imparte las enseñanzas que integran el sistema educativo deberá adquirir las competencias y habilidades relativas al emprendimiento, la iniciativa empresarial, la igualdad de oportunidades en el entorno empresarial, y la creación y desarrollo de empresas, a través de la formación inicial o de la formación permanente del profesorado» Para ello, «el Ministerio de Educación, Cultura y Deporte, en colaboración con las Comunidades Autónomas, promoverá que los programas de formación permanente del profesorado incluyan contenidos referidos al emprendimiento, la iniciativa empresarial y la creación y desarrollo de empresas».

Todo queda pendiente, eso sí, de desarrollo posterior.

\subsection{El papel de las oficinas de apoyo a emprendedores en la Universidad}

Para dar respuesta a lo establecido en el artículo 5 de la ya citada Ley de emprendedores y su internacionalización, es necesario que las universidades se doten de estructuras adecuadas para ello. Son las denominadas oficinas universitarias de apoyo a los emprendedores. Su función principal es difundir cultura emprendedora, formación específica en materia de emprendimiento y, sobre todo, prestar el asesoramiento preciso para la creación de empresas (aunque también otras concreciones de iniciativas emprendedoras no empresariales, como es el caso de organizaciones no lucrativas, asociaciones y fundaciones fundamentalmente). Pero estas estructuras no sólo contribuyen al nacimiento de nuevas iniciativas empresariales, sino que también desempeñan un papel clave en su crecimiento y consolidación.

Hay experiencias emblemáticas como CIADE (Universidad Autónoma de Madrid), UNIEMPRENDE (Universidad de Santiago de Compostela), UPV-Ideas (Universidad Politécnica de Valencia) o más recientemente la Oficina Complutense del Emprendedor (Compluemprende - Universidad Complutense de Madrid). Y son numerosos los parques científicos y tecnológicos que surgen al amparo de las Universidades y en estrecha colaboración con las Oficinas de Transferencia de Resultados de la Investigación (OTRIs).

A lo anterior se suma la aparición de Cátedras extraordinarias relacionadas con el emprendimiento. Es el caso, por ejemplo de la red de Cátedras BANJACA Jóvenes Emprendedores, las Cátedras sobre Economía Social localizadas en diversas Universidades españolas o la Cátedra de Empresa Individual y Trabajo Autónomo de la Universidad Complutense de Madrid que es la primera que se crea centrada en el emprendimiento individual, objeto de estudio en este trabajo. 
Pues bien, la iniciativa de nuestras universidades consistente en proveer de una estructura apropiada para apoyar las propuestas de actividades emprendedoras que pudieran formular los integrantes de la comunidad universitaria es fundamental para contribuir a la difusión de la cultura emprendedora y facilitar, mediante la formación adecuada y el asesoramiento preciso, el que surjan empresas (y también otras organizaciones no empresariales) desde la Universidad, tanto de base tecnológica como no tecnológicas (siempre basadas en el conocimiento).

En estas oficinas de apoyo desempeñan un papel fundamental los técnicos encargados tanto de las labores de asesoramiento como de formación. En general se trata de personal muy cualificado pero que no siempre conoce en profundidad las particularidades de algunas fórmulas empresariales, en particular, las empresas de participación (tanto sociedades cooperativas, como sociedades laborales y empresas individuales — trabajo autónomo-). Esto supone una limitación muy importante ya que en ocasiones derivan a los potenciales emprendedores hacía otras fórmulas empresariales basándose en tópicos que se alejan de la realidad por desconocimiento de aspectos muy concretos que les atañen. A ello se suma el que normalmente los usuarios de los servicios de estas oficinas tampoco tienen una formación adecuada que les haga demandantes de formas jurídicas empresariales más allá de la sociedad de responsabilidad limitada, conocida por todos.

A esto ha sido sensible la Confederación Empresarial Española de la Economía Social (CEPES) que, recientemente, ha firmado un convenio de colaboración con la Conferencia de Rectores de las Universidades Españolas (CRUE) en el contexto de una «jornada de sensibilización sobre la importancia del fomento del espíritu emprendedor de la economía social en las Universidades españolas». Es una iniciativa de interés que tendría que soportarse precisamente en las oficinas de apoyo a emprendedores de las que disponen muchas de nuestras Universidades.

\subsection{Panel de expertos del estudio. Oficinas técnicas consultadas}

En el estudio realizado se ha contado con un panel de expertos integrado por profesionales dedicados al asesoramiento de estudiantes universitarios interesados en crear sus propias empresas incluye a técnicos de las cuatro oficinas técnicas especializadas de referencia (Compluemprende, CIADE, Instituto IDEAS y Uniemprende) y a técnicos de otras Universidades que no disponen de dichas oficinas pero que tienen una trayectoria contrastada en este ámbito. 
Del total de Universidades representadas en el panel 5 de ellas son públicas y 2 privadas (Universidad CEU San Pablo y ESADE).

\subsection{Resultados del estudio}

Las principales conclusiones del estudio realizado con el grupo de expertos que forman parte de las oficinas técnicas de apoyo a los estudiantes-emprendedores en las Universidades son las siguientes:

- Un porcentaje muy significativo de las iniciativas que se presentan para solicitar el asesoramiento técnico en las estructuras universitarias de apoyo a emprendedores se caracterizan por tratarse de proyectos individuales, no societarios, algo que lleva inherente el que los futuros emprendedores consideren la posibilidad de trabajo autónomo entre sus opciones preferidas (el número de promotores condiciona la forma jurídica finalmente elegida).

- La percepción que tienen los técnicos de las oficinas de apoyo es que los potenciales emprendedores lo son mayoritariamente por las dificultades para encontrar trabajo por cuenta ajena, hecho que pone en evidencia la escasa cultura emprendedora de nuestros estudiantes universitarios.

- Al emprendimiento empresarial individual se le reconoce una importante flexibilidad y adaptabilidad al entorno y unos costes de puesta en marcha reducidos, lo que le hace una fórmula atractiva. Sin embargo no se piensa que a través del trabajo autónomo se logre un deseable desarrollo futuro profesional ni un nivel retributivo considerable.

- Los asesores perciben que los estudiantes-emprendedores tienen un conocimiento muy bajo de lo que significa ser trabajador por cuenta propia y consideran, de forma generalizada, que deben haber formación universitaria específica sobre esta materia.

- Se perciben los problemas de financiación como los fundamentales con los que se enfrenta el colectivo de empresarios individuales demandándose en consecuencia medidas que mejoren el acceso a la financiación por parte de este colectivo. Con todo, la financiación y en particular la contracción del crédito que ha provocado unas tensiones de tesorería insostenibles no son algo exclusivo del colectivo objeto de estudio sino de cualquier microempresa (y no solo) como consecuencia de la coyuntura económica actual. 
- Ante la percepción del incremento de la economía sumergida, puede haber la tentación de asociar este asunto con el trabajo autónomo, algo sin duda negativo para el conjunto.

- El incuestionable inconveniente que supone para un empresario individual que es trabajador autónomo el que responde de las deudas sociales con todo su patrimonio no es algo que pueda considerarse relevante (en términos generales) en aquellas iniciativas que surgen de estudiantes universitarios (habida cuenta de que lo normal es que no dispongan de patrimonio).

- En la actualidad las reglas de acceso al pago único de la prestación por desempleo para realizar actividad por cuenta propia permite obtener el 100 por 100 del derecho consolidado siempre que se trate de jóvenes menores de 30 años, algo no suficientemente conocido entre los asesores.

Sobre la base de todo lo anterior cabe destacar:

- El trabajo autónomo es una de las formas empresariales más elegidas por los estudiantes que solicitan apoyo de las oficinas técnicas de asesoramiento a emprendedores universitarios.

- En consecuencia, el conocimiento de la realidad del trabajo autónomo por parte de los expertos que actúan como prescriptores es fundamental para un adecuado asesoramiento. Deben conocer bien la Ley del Estatuto del Trabajo Autónomo y su desarrollo, manteniéndose siempre actualizados sobre este asunto (como por ejemplo, en el acceso al pago único de la prestación por parte de jóvenes). $Y$ es muy importante que sepan transmitir que algunos problemas como el del crédito o el retraso de pago de las Administraciones Públicas, que afectan a empresarios individuales particularmente, son propios en general de entidades de reducida dimensión y responden también a una situación coyuntural, por lo que cabe prever un cambio de tendencia más adelante.

- El mayor conocimiento de la realidad que representan les permitirá mejorar la imagen que tienen del colectivo, dejando aparte ciertos tópicos muy alejados de lo que realmente ocurre. Esto se traducirá en un estímulo a que nuevas iniciativas se concreten a través de empresarios individuales. Con relación a este asunto es importante disociar actividades ilegales que forman parte de la economía informal con el concepto de trabajo autónomo, que como tal concepto ha de situarse siempre en el marco de nuestro ordenamiento jurídico, tanto en términos fiscales como de la Seguridad Social.

- Además de la formación de los cuadros técnicos de asesoramiento, es muy importante la formación del alumnado sobre 
la empresa individual y el trabajo autónomo, hasta ahora claramente insuficiente. En este sentido las Cátedras de trabajo autónomo son un instrumento sin duda eficaz, como así se ha demostrado con las experiencias existentes. Es muy importante conseguir sinergias mediante el funcionamiento en red de las Cátedras y grupos de investigación que trabajan sobre la materia. Y muy deseable la colaboración entre Cátedras, redes de Cátedras y oficinas técnicas de apoyo a emprendedores, en particular, las OTRI.

- Las estructuras de apoyo deben intensificar sus esfuerzos en la difusión de cultura emprendedora que contribuya a cambiar la actual tendencia a emprender, tanto individual como colectivamente, por la imposibilidad de encontrar un empleo.

\section{Conclusiones}

En España existe un importante problema de desempleo, que a raíz de la actual crisis económica se ha agravado de forma considerable durante los últimos años, consecuencia de la reducción del número de empresas que se crean, y del incremento del cierre, y las reducciones de plantilla, de las ya existentes. Los jóvenes son uno de los colectivos más afectados por el desempleo, la temporalidad de los contratos, y las jornadas a tiempo parcial, por lo que, ante la dificultad de encontrar empleo por cuenta ajena, el emprendimiento, y en concreto el emprendimiento individual o trabajo autónomo puede suponer una alternativa al trabajo asalariado que les permita tanto incorporarse, como mantenerse en el mercado laboral, y mejorar sus condiciones de trabajo.

No cabe duda de que el emprendimiento constituye la base del crecimiento económico, y es ahí donde las empresas de participación de trabajo asociado pueden desempeñar un papel clave en la recuperación económica de nuestro país. Durante los últimos años la tendencia ha sido hacia la reducción en el ritmo de creación de empresas personas físicas, si bien, los últimos datos de los años 2011 y 2012 son más positivos que los de los años previos, por lo que invitan a pensar en el optimismo y en la recuperación de la senda de crecimiento.

El trabajo autónomo, al igual que ocurre con otras fórmulas de empresas de participación como son las sociedades cooperativas o las sociedades laborales, son formas de empresas que contribuyen al desarrollo territorial, en las que es inherente a su condición una especial sensibilidad en términos de responsabilidad social, que no se deslocalizan y que permiten así una mayor integración y cohesión social apor- 
tando al mismo tiempo riqueza y empleo de calidad y estable allí dónde se encuentran. Es por ello que también son fórmulas adecuadas para dar respuesta a los retos del cambio demográfico, como pueden ser el relevo generacional, la igualdad efectiva de la mujer, o la incorporación de la población inmigrante al mercado laboral.

Como se desprende del estudio, es habitual que los nuevos emprendedores tengan en mente la puesta en marcha de proyectos empresariales de forma unipersonal. Pero esto no significa que no aumenten su dimensión en momentos posteriores. Las empresas de participación de trabajo asociado constituyen de hecho el vehículo adecuado para que las iniciativas empresariales llevadas a cabo por trabajadores autónomos, o empresarios individuales, se concreten bien en sociedades laborales, o en sociedades cooperativas de trabajo asociado, cuando necesiten aumentar su dimensión y requieran de formas jurídicas de carácter societario para afianzar sus negocios.

Con todo, los jóvenes universitarios españoles, afectados por una elevadísima tasa de desempleo, siguen mostrando una escasa vocación emprendedora. Si a ello sumamos la limitada oferta educativa en materia de emprendimiento individual existente en los planes de estudios de educación superior, se evidencia la necesidad de medidas que impulsen el emprendimiento en general y el individual en particular en este colectivo.

Evidentemente las oficinas técnicas universitarias de apoyo en materia de emprendimiento juegan un papel determinante en este sentido, promoviendo y difundiendo la cultura emprendedora y acompañando a los emprendedores en las fases iniciales de sus proyectos, prestándoles asesoramiento y formación.

Los profesores también desempeñan un rol muy importante, porque su capacidad de transmitir la realidad del emprendimiento y del trabajo autónomo contribuirá a un mejor conocimiento del colectivo descartándose así ciertos tópicos que se le asocian muy alejados de la realidad.

Es precisa así una coordinación entre profesorado implicado en materia de emprendimiento (fundamentalmente responsables de Cátedras de creación de empresas y similares) y oficinas técnicas de apoyo a estudiantes universitarios emprendedores que, en materia de emprendimiento individual y, en concreto, de trabajo autónomo, persiga la consecución de los siguientes objetivos:

1. Promover asignaturas relacionadas con el trabajo autónomo en las Universidades, especialmente en los estudios de Administración y Dirección de Empresas, Economía y Derecho. 
2. Insistir en el carácter empresarial de los trabajadores autónomos como empresarios individuales que desarrollan una actividad económica (productiva, generalmente de servicios), de participación con objetivo coincidente con los objetivos empresariales en términos de consecución de un mayor valor vía contraprestaciones económicas y financieras.

3. Informar de los progresos relacionados con la equiparación de las prestaciones sociales de los trabajadores autónomos y de los trabajadores por cuenta ajena.

4. Informar de las posibles alternativas que ofrece el emprendimiento en general, y el emprendimiento individual en particular.

5. Formar a los estudiantes en los derechos que actualmente tienen los trabajadores autónomos y en las medidas que tienden a favorecerlos.

6. Recalcar las ventajas y el potencial del trabajo autónomo.

7. Estudiar de manera concreta los problemas a los que se enfrentan los trabajadores autónomos en la actualidad para poder formar a los potenciales emprendedores con base en el optimismo y las oportunidades que ofrece esta vía de emprendimiento a través de herramientas concretas de apoyo.

8. Apoyar las iniciativas que desde las propias Universidades se vienen desarrollando para promover el espíritu emprendedor para lo cual es necesario reforzar la formación de técnicos encargados de las labores de asesoramiento y formación en las particularidades de algunas fórmulas empresariales, en particular, las empresas de participación (tanto sociedades cooperativas, como sociedades laborales y empresas individuales — trabajo autónomo-) para que estas fórmulas sean tenidas en cuenta y no se derive en otras estructuras basándose en tópicos que se alejan de la realidad por desconocimiento de aspectos muy concretos que les atañen.

\section{Bibliografía}

ALEMANY, L.; ÁlVAREZ, C.; PLANELLAS, M. y URBANO, D. Libro Blanco de la iniciativa emprendedora en España. Esade Enterpreneurship Institute. Barcelona, 2011.

ALONSO NUEZ, M. ${ }^{a}$ J.; GAVE GÓRRIZ, C. «El emprendedor y la empresa: una revisión teórica de los determinantes a su constitución», Acciones e Investigaciones Sociales, n. ${ }^{\circ} 26$, julio 2008, pp. 5-44. 
ATA. Federación Autónomos. Informe jóvenes emprendedores - Unión Europea, 2011. Disponible en internet en: http://www.ata.es/imagenes/publicacionesPdf/publicacion55.pdf

BEL DURÁN, P. El trabajo autónomo desde la perspectiva del estudiante universitario. Una aproximación desde los estudios de ADE. Ponencia presentada al I Congreso de la Red Universitaria de Trabajo Autónomo (RUTA), Santiago de Compostela, 28 y 29 de octubre de 2010.

BEL DURÁN, P.; FERNÁNDEZ GUADAÑO, J.; GARCÍA-GUTIÉRREZ FERNÁNDEZ, C.; LEJARRIAGA PÉREZ DE LAS VACAS, G. y MARTín LÓPEZ, S. "La percepción del emprendimiento individual en el ámbito universitario». Ponencia presentada en el Encuentro de Institutos y Centros Universitarios en Economía Social, Valencia, 15 y 16 de diciembre de 2011.

BEL DURÁN, P.; FERNÁNDEZ GUADAÑO, J.; GARCÍA-GUTIÉRREZ FERNÁNDEZ, C.; LEJARRIAGA PÉREZ DE LAS VACAS, G. y MARTíN LÓPEZ, S. (2008). «Realidad económica del trabajo autónomo: Fuentes estadísticas». En: GARCÍA NOVOA, C. y LEJARRIAGA PÉREZ DE LAS VACAS, G. (Directores). Realidad económica del trabajo autónomo: Fuentes estadísticas y régimen fiscal, Grupo Editorial Cinca, Madrid, 2008, pp. 39-110.

BEL DURÁN, P.; FERNÁNDEZ GUADAÑO, J.; GARCÍA-GUTIÉRREZ FERNÁNDEZ, C.; LEJARRIAGA PÉREZ DE LAS VACAS, G. y MARTíN LÓPEZ, S. «EI apoyo al emprendimiento individual universitario desde las oficinas de emprendedores». Ponencia presentada a las XIV Jornadas de Investigadores en Economía Social organizadas por CIRIEC-España, San Sebastián y Oñati, 21 a 22 de junio de 2012.

BENAVIDES ESPINOSA, M. ${ }^{a}$ M.; SÁNCHEZ GARCÍA, M. ${ }^{a}$ I.; LUNA AROCAS, R. «El proceso de aprendizaje para los emprendedores en la situación actual: un análisis cualitativo en el ámbito universitario», Dirección y Organización, n. ${ }^{\circ} 30$, abril 2004, pp. 34-48.

CLARK, B. "Creando universidades emprendedoras en Europa», Revista valenciana d'estudis autonòmics, n. ${ }^{\circ}$ extra 21, 1996, pp. 373-392.

CLEMENTE LÓPEZ, J.; DÍAZ FONSECA, M. y MARCUELLO SERVÓS, C. "Sociedades Cooperativas y Sociedades laborales en España: Estudio de su contribución a la creación de empleo y al crecimiento económico», REVESCO. Revista de Estudios Cooperativos, n. ${ }^{\circ}$ 98, segundo cuatrimestre 2009, pp. 35-69.

COQUE MARTÍNEZ, J.; LÓPEZ MIELGO, N. y LOREDEO FERNÁNDEZ, E. J. «Fomento de la cultura emprendedora e innovadora entre el alumnado universitario del campus politécnico de Gijón», Forum Calidad, n. ${ }^{\circ}$ 177, 2007, pp. 42-50.

CORTI, E. y RIVIEZZO, A. «Hacia la universidad emprendedora: un análisis del compromiso de las universidades italianas en el desarrollo económico y social», Economía Industrial, n. ${ }^{\circ} 368,2008$, pp. 113-124.

DÍAZ BRETONES, F. «Actitudes, motivación y creación de empresas: el caso de los emprendedores en sistema cooperativo», Revista de Estudios Cooperativos (REVESCO), n. ${ }^{\circ} 84$, tercer cuatrimestre 2004, pp. 37-52.

ESPAÑA. Ley 14/2013, de 27 de septiembre, de apoyo a los emprendedores y su internacionalización. B.O.E., 233, de 28 de septiembre. 
ETZKOWITZ, H. «El auge de la Universidad emprendedora», Iniciativa emprendedora y empresa familiar, n. ${ }^{\circ} 41,2003$, pp. 13-33.

FERNÁNDEZ GUADAÑO, J.; MARTÍN LÓPEZ, S. y LEJARRIAGA PÉREZ DE LAS VACAS, G. "Retos del trabajo autónomo para afrontar la crisis económicofinanciera». Economistas. Revista del Colegio de Economistas, n. ${ }^{\circ} 124$, 2010, pp. 99-113.

GARCÍA TABUENCA, A.; CRESPO ESPERT, J. L.; PABLO MARTíN, F. y CRECENTE ROMERO, F. «Emprendedores y empresas en España. Un enfoque ecléctico». Economía Industrial, n. ${ }^{\circ} 367,2008$, pp. 51-65.

GARCÍA-GUTIÉRREZ FERNÁNDEZ, C. "La empresa de participación: características que la definen. Virtualidad y perspectivas en la sociedad de la información», CIRIEC-España: Revista de economía pública, social y cooperativa, n. ${ }^{\circ} 40$, abril 2002, pp. 99-122.

GARCÍA-GUTIÉRREZ FERNÁNDEZ, C. y FERNÁNDEZ GUADAÑO, J. "El empresario individual: situación actual y propuesta de actuación futuras», CIRIECEspaña. Revista de Economía Pública, Social y Cooperativa, n. ${ }^{\circ} 52$, agosto 2005, pp. 201-217.

GARCÍA-GUTIÉRREZ FERNÁNDEZ, C. y LEJARRIAGA PÉREZ DE LAS VACAS, G. (Directores). Libro Blanco de las empresas de participación de trabajo (economía social) de la Ciudad de Madrid, Madrid Emprende, Madrid, 2004.

GARCÍA-GUTIÉRREZ FERNÁNDEZ, C.; LEJARRIAGA PÉREZ DE LAS VACAS, G.; BEL DURÁN, P.; FERNÁNDEZ GUADAÑO, J. y MARTíN LÓPEZ, S. «El emprendimiento y el empleo a través de la empresa individual: contraste de las fuentes estadísticas», REVESCO. Revista de Estudios Cooperativos, n. ${ }^{\circ}$ 96, 2008, pp. 16-48.

GARCÍA-GUTIÉRREZ FERNÁNDEZ, C.; LEJARRIAGA PÉREZ DE LAS VACAS, G.; FERNÁNDEZ GUADAÑO, J. y MARTÍN LÓPEZ, S. El trabajo autónomo desde la perspectiva de la política empresarial. En: SALINAS RAMOS, F. y HERRANZ DE LA CASA, J. M. ${ }^{a}$ (Editores). El Trabajo Autónomo en España, Universidad Católica de Ávila, Salamanca, 2006, pp. 97-127.

GOÑl GAZTELU, E. "Se necesitan emprendedores. ¿Tiene la Universidad algo que ofrecer? La educación basada en competencias como respuesta», Boletín de Estudios Económicos, n. ${ }^{\circ} 168$, diciembre 1999.

GRÁVALOS, M. A.; POMARES, I. "La adaptación de las Sociedades Laborales a la evolución del ciclo económico. Un estudio empírico para las diferentes comunidades autónomas», CIRIEC-España, Revista Pública, Social y Cooperativa, n. ${ }^{\circ} 38,2001$, pp. 33-55.

ÍBAÑEZ ROMERO, M. ${ }^{a}$ A. Actitudes emprendedoras de los estudiantes universitarios, Universidad de Deusto, Bilbao, 2002.

LEJARRIAGA PÉREZ DE LAS VACAS, G.; BEL DURÁN, P. y MARTíN LÓPEZ, S. "Las empresas de trabajo asociado como alternativa de emprendimiento para los jóvenes». Ponencia presentada en el VI Congreso Internacional de RULESCOOP «Soluciones de la Economía Social y Solidaria a un mundo en Crisis» celebrado entre los días 7 y 9 de septiembre de 2011.

LEJARRIAGA PÉREZ DE LAS VACAS, G. "Las oficinas de apoyo a emprendedores en la Universidad y promoción del trabajo autónomo. El caso de Com- 
pluemprende». Ponencia presentada al I Congreso Universitario del Trabajo Autónomo y la Empresa Individual. Santiago de Compostela, 28 y 29 de octubre de 2010.

LEJARRIAGA PÉREZ DE LAS VACAS, G.; BEL DURÁN, P.; MARTÍN LÓPEZ, S. «EI emprendimiento colectivo como salida laboral de los jóvenes: análisis del caso de las empresas de trabajo asociado». Ponencia presentada a las $I V$ Jornadas Virtuales. Publicación: http://www.ucm.es/info/aecoop/comunicacion. php. Lugar celebración: En línea. 14 de octubre de 2011.

LEJARRIAGA PÉREZ DE LAS VACAS, G.; BEL DURÁN, P.; MARTíN LÓPEZ, S. «Emprendimiento universitario bajo fórmulas de empresas de participación o economía social». Ponencia presentada a las III Jornadas de la Cátedra de Economía Social de la Universidad de Murcia. Murcia, 3 de noviembre de 2011.

LEJARRIAGA PÉREZ DE LAS VACAS, G.; BEL DURÁN, P.; MARTíN LÓPEZ, S. «Un estudio sobre las posibilidades de canalización de iniciativas universitarias emprendedoras en fórmulas de empresas de participación (Economía Social)». Ponencia presentada al I Encuentro sobre Emprendimiento Social. Valencia, 15 y 16 de diciembre de 2011.

LEJARRIAGA PÉREZ DE LAS VACAS, G.; MARTÍN LÓPEZ, S. «El nacimiento de nuevas iniciativas emprendedoras en el ámbito universitario: el apoyo prestado desde Compluemprende». Ponencia presentada a las XIII Edición de las Jornadas de Investigadores en Economía Social. CIRIEC-España. Zaragoza, 21 y 22 de octubre de 2010.

MARTíN LÓPEZ, S.; FERNÁNDEZ GUADAÑO, J.; BEL DURÁN, P.; LEJARRIAGA PÉREZ DE LAS VACAS, G. "Necesidad de medidas para impulsar la creación de las empresas de participación desde los diferentes niveles de enseñanza», Revista CIRIEC-España. En prensa.

MELGAREJO MOLINA, Z.; ARCELUS, F.J. y SIMÓN, K. "Una evaluación crítica del potencial de supervivencia de las sociedades laborales», CIRIEC- España, Revista de Economía Pública, Social y Cooperativa, n. ${ }^{\circ}$ 59, octubre 2007, pp. 181-202.

MORALES GUTIERREZ, A.C. y ARIZA MONTES, A. «Valores en la juventud y emprendimiento individual y colectivo». En: IV Jornadas sobre «La percepción de la Economía Social y del emprendimiento (individual o colectivo) por parte de la juventud actual»», organizadas por AECOOP, celebradas el 17 de octubre de 2011.

MORALES-GUALDRÓN, S. T. «El emprendedor académico y la decisión de crear empresa: un análisis del caso español». Ponencia presentada al // Congreso Internacional y X Seminario Iberoamericano Motiva: La Universidad y El Emprendimiento, celebrado entre el 27 y el 30 de octubre de 2009 en Valencia.

PUNSET, E. «¿Por qué no abundan en España los universitarios emprendedores?», Revista $A P D$, n. ${ }^{\circ} 209$, mayo 2006, pp. 36-38. 